\title{
Type 4 Luschka Duct - A Rare Anatomical Variant to be Wary Of
}

\author{
Cameron James Parkin MBBS, BMedSci ${ }^{1}$ \\ Kenneth Buxey, MBBS (Hons) ${ }^{1}$ \\ Catriona A McLean BSc, MBBS, FRCPA, MD, FFSc, FAHMS 2
}

1. Department of General Surgery, The Alfred Hospital, Melbourne, Victoria, Australia

2. Department of Anatomical Pathology, The Alfred Hospital, Melbourne, Victoria, Australia

Total Word Count - 750

Dr. Cameron James Parkin - Department of General Surgery, The Alfred Hospital, Melbourne, Victoria Australia Address - 55 Commercial Road, Melbourne Victoria 3004

Email - cameronjparkin@gmail.com

Mobile Phone Number - 0437060192

This is the author manuscript accepted for publication and has undergone full peer review but has not been through the copyediting, typesetting, pagination and proofreading process, which may lead to differences between this version and the Version of Record. Please cite this article as doi: 10.1111/ans.14407

This article is protected by copyright. All rights reserved. 
The authors are not current recipients of a research scholarship. The paper is not based on a previous communication to a society/meeting

Dear Editor,

\section{Type 4 Luschka Duct - A Rare Anatomical Variant to be Wary Of}

Case Report

A 41-year-old female represented acutely with crescendo biliary colic symptoms. Sonography revealed cholelithiasis with an impacted stone. The common bile duct measured $8 \mathrm{~mm}$, with no intraductal calculi visualised. Inflammatory markers were not elevated and liver function tests were normal. An emergency laparoscopic cholecystectomy was performed which demonstrated gallbladder inflammation and a large impacted gallstone. A critical view was attained and operative cholangiography was unremarkable (Figure 1). There were no immediate post-operative complications and the patient was discharged 24 hours post operatively.

Fig. 1.

Four days post operatively, the patient represented acutely with sudden onset right upper quadrant pain and associated sweats and nausea. She was tachycardic with a heart rate of 110 . Her serum bilirubin was 7 and CRP 20. Histopathology from the index operation showed acute on chronic cholecystitis and additionally a subserosal $9 \mathrm{~mm}$ area of thickening just adjacent to the liver bed resection margin within which there were ducts lines by a columnar epithelium that were cytokeratin 7 immunoreactive forming a subserosal cluster of ducts consistent with ducts of Luschka. These were only discernible microscopically not macroscopically (Figure 2a, b). Urgent magnetic resonance cholangiopancreatography (MRCP) was undertaken which found a complex collection at the gallbladder fossa and perihepatic fluid. On the basis of this, relook laparoscopy was arranged.

Fig. 2

At laparoscopy moderate volume biliary fluid was demonstrated without a clear source. A washout and insertion of a drain tube was undertaken. No accessory biliary ducts were visualised. Low volume bile leakage persisted and so an endoscopic retrograde cholangio-pancreatography (ERCP) was then performed which showed no leak and a biliary stent was placed. The patient went on to make a full recovery.

\section{Discussion}

Within the surgical literature anatomical variations of the biliary tree are well described. Bile leaks are the main feared complication of cholecystectomy. ${ }^{1}$ Minor bile leaks are usually attributed to either cystic duct stump leakage or from a duct of Luschka. The duct of Luschka refers to an accessory bile duct that originates from the right hepatic lobe, and drains into the right or common hepatic duct or directly into the gallbladder ${ }^{1}$. Typically these ducts are not accompanied by a 
portal vein or hepatic artery as in the portal triad, and may or may not lie within the liver capsule. Originally described in 1863 by the German anatomist von Luschka, it is now recognised that there is even great anatomical variance in the accessory ducts themselves ${ }^{2}$. As such there is now a growing trend to refer to these ducts as subvesical bile ducts ${ }^{2}$. The prevalence of these ducts within the general population is not well described ${ }^{1}$. One systematic review suggested a $4 \%$ prevalence of Luschka ducts in the general population.

\section{Fig. 3}

Schenlldorfer ${ }^{2}$ et al describe Luschka ducts as being of four main types (Figure 3). Types 1 and 2 are aberrant posterior sectoral ducts that are in proximity to the cystic plate. These are intrahepatic and if dissection proceeds on the gallbladder side of the cystic plate they will be seen on cholangiography but not seen at laparoscopy. Type 3 is a macroscopic duct that drains directly from the liver into the gallbladder. This duct can potentially be visualised laparoscopically but is excluded from a conventional cholangiogram. Type 4 is a collection of microscopic ducts that traverse the cystic plate. This type is not identifiable laparoscopically or at cholangiography and thus is likely to be injured during a routine cholecystectomy. The likelihood of clinical sequlae in this setting is not described. In our case, the patient's histopathology was consistent with a type 4 duct of Luschka.

Management of duct of Luschka injury is informed by subtype. Type 1 and 2 can generally be avoided entirely by correct plane of dissection. In cases of injury Type 2 can be ligated or clipped as the right postero-lateral liver segments also drain via a true posterior sectoral duct. Injury to type 1 may be very difficult to manage as the duct is the true segmental drainage channel of segment 6 of the liver and in cases of failed ERCP these patients may need segmental liver resection to manage bile leak. Type 3 ducts can be clipped at operation provided the anatomy is perfectly understood. Type 4 injuries are difficult to avoid but should resolve in either a self-limiting manner or with endoscopic drainage.

In summary, we have described a case of a histopathologically proven Type 4 Luschka duct which is a rare entity but important to remember when thinking about the post cholecystectomy bile leak patient.

\section{References}

1. Frakes JT, Bradley SJ. Endoscopic stent placement for biliary leak from an accessory duct of Luschka after laparoscopic cholecystectomy. Gastrointest Endosc. 1993; 39: 90-92

2. Schnelldorfer T, Sarr MG, Adams DB. What is the duct of Luschka? - A systematic review. J Gastrointest Surg. 2012;16: 656-662

3. Ramia JM, Muffak K, Mansilla A, Villar J, Garrate D, Ferron JA. Postlaparoscopic cholecystectomy bile leak secondary to an accessory duct of Luschka. JSLS. 2005; 9: 216-217

\section{Figures Legend}

Fig. 1. Intra-operative Cholangiography following cholecystectomy demonstrating no leak seen

Fig. 2. Thickened, inflamed gall bladder with subserosal cluster of ducts (arrows) just adjacent the liver bed resection margin (a) and (b) high power magnification of the ducts showing a bland columnar epithelium in keeping with ducts of Luschka.

Fig. 3 Types of Luschka Ducts: type 1 - segmental, type 2 - accessory, type 3 hepaticocholecystic, type 4 - aberrant subvesical bile duct (from Schenlldorfer et. al, 2012, p. 660) 
Cameron J. Parkin MBBS, BMedSci ${ }^{1}$

Kenneth Buxey, MBBS (Hons) ${ }^{1}$

Catriona A McLean BSc, MBBS, FRCPA, MD, FFSc, FAHMS²

Department of General Surgery, The Alfred Hospital ${ }^{1}$,

Department of Anatomical Pathology, The Alfred Hospital ${ }^{2}$

Melbourne, Victoria, Australia

This article is protected by copyright. All rights reserved. 

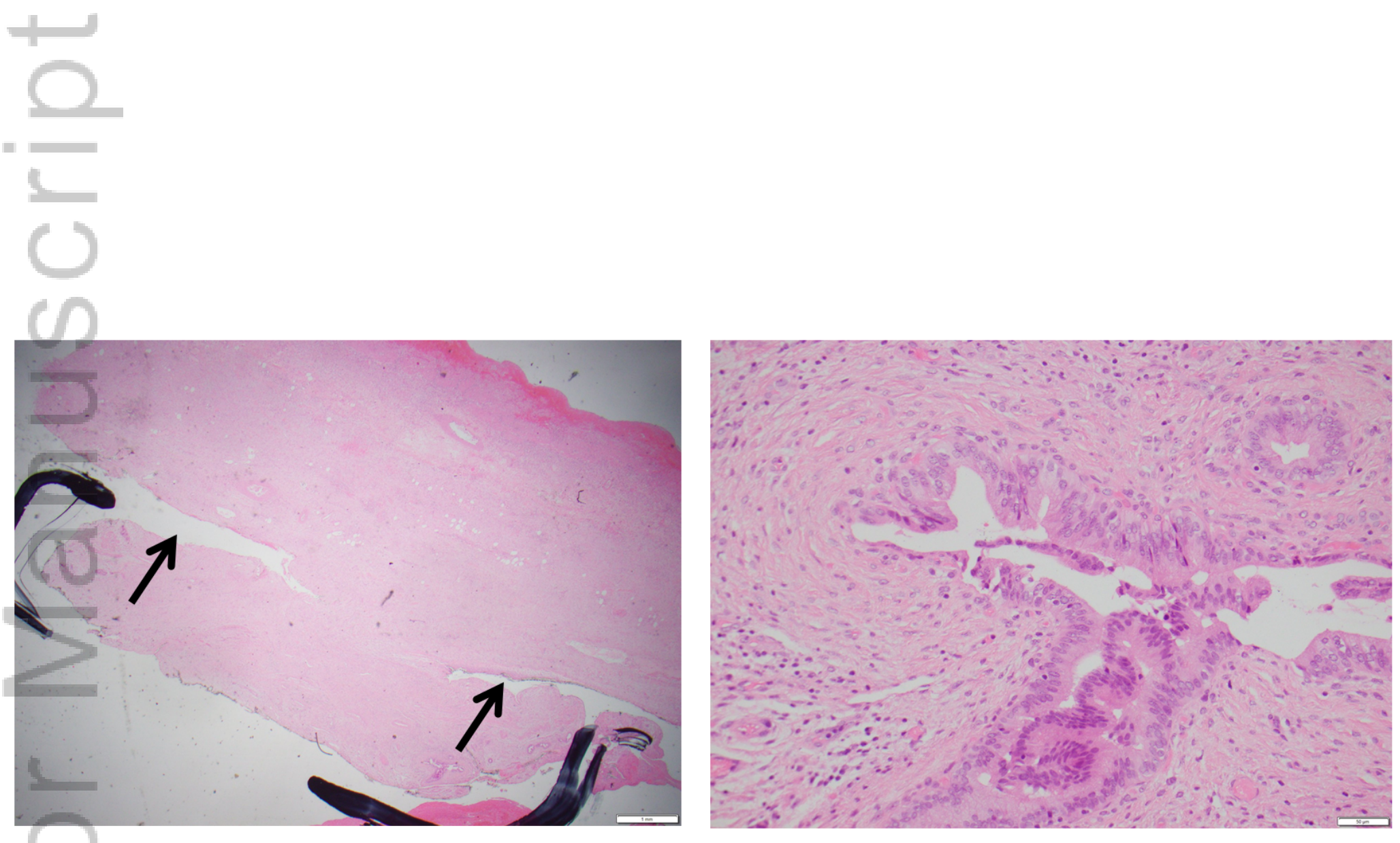

Figure 2.PNG

This article is protected by copyright. All rights reserved. 


\section{University Library}

\section{- M M I E E R VA A gateway to Melbourne's research publications}

Minerva Access is the Institutional Repository of The University of Melbourne

Author/s:

Parkin, CJ;Buxey, K;McLean, CA

Title:

Type 4 Luschka duct: a rare anatomical variant to be wary of

Date:

2019-07-01

Citation:

Parkin, C. J., Buxey, K. \& McLean, C. A. (2019). Type 4 Luschka duct: a rare anatomical variant to be wary of. ANZ JOURNAL OF SURGERY, 89 (7-8), pp.E315-E316. https:// doi.org/10.1111/ans. 14407.

Persistent Link:

http://hdl.handle.net/11343/283759 